\title{
Associations between Problematic Smartphone Use, Unhealthy Behaviors, and Mental Health Status in Korean Adolescents: Based on Data from the 13th Korea Youth Risk Behavior Survey (2017)
}

\author{
Hae Ran Kim ${ }^{1 凶}$ and Mi Ah $\mathrm{Han}^{2}$ \\ ${ }^{1}$ Department of Nursing, College of Medicine, Chosun University, Gwangju, Republic of Korea \\ ${ }^{2}$ Department of Preventive Medicine, College of Medicine, Chosun University, Gwangju, Republic of Korea
}

\begin{abstract}
Objective We aimed to assess the associations between problematic smartphone use, unhealthy behaviors, and mental health status among adolescents.

Methods The data for this cross-sectional study were obtained from the 13th Korea Youth Risk Behavior Survey (2017). From among the 62,276 adolescents who participated in this nationwide web-based survey, 54,603 (87.7\%) who used smartphones were selected as the study population. Unhealthy behaviors included smoking, drinking, physical inactivity, skipping breakfast, and fast food consumption. For the examination of mental health status, we considered sleep disturbances, stress, depressive symptoms, suicidal ideation, and suicide attempts. The associations between problematic smartphone use, unhealthy behaviors, and mental health were analyzed using multiple logistic regression analyses.

Results More than four hours of use on weekdays (31.3\%) and weekends (61.3\%) and the use of smartphones for communication (46.9\%) were associated with unhealthy behaviors and mental health problems. Furthermore, adolescents who experienced conflicts with family (22.3\%) and friends (25.8\%) and academic problems (3.4\%) were likely to have health problems.

Conclusion The results suggest that problematic smartphone use may disrupt adolescents' health. Therefore, there is a need for prevention programs for problematic smartphone use at home and at school to improve adolescents' health.
\end{abstract}

Psychiatry Investig 2020;17(12):1216-1225

Key Words Problematic smartphone use, Health behavior, Mental health, Adolescents.

\section{INTRODUCTION}

With the greater portability and connectivity they offer, smartphones are being increasingly used in everyday life. ${ }^{1}$ In South Korea, $89.5 \%$ of the total population, including $97.2 \%$ of adolescents, used smartphones in $2018 .{ }^{2}$ In this context, recent studies have highlighted the negative impact of adolescents' smartphone use..$^{3-5}$ Compared to people of other age groups, adolescents, may be more vulnerable to the negative effects of smartphone use because they lack the ability to

Received: January 7, 2020 Revised: April 26, 2020

Accepted: October 11, 2020

$\triangle$ Correspondence: Hae Ran Kim, RN, PhD

Department of Nursing, College of Medicine, Chosun University, 309 Pilmundaero, Dong-gu, Gwangju 61452, Republic of Korea

Tel: +82-62-230-6317, E-mail: rahn00@chosun.ac.kr

(a) This is an Open Access article distributed under the terms of the Creative Commons Attribution Non-Commercial License (https://creativecommons.org/licenses/bync/4.0) which permits unrestricted non-commercial use, distribution, and reproduction in any medium, provided the original work is properly cited. manage impulsive behaviors. ${ }^{6}$ This problem is not limited to South Korea, as demonstrated by reports that $41.9 \%$ of Spanish adolescents ${ }^{7}$ and $21.3 \%$ of Chinese adolescents ${ }^{8}$ exhibited problematic smartphone use.

Previous studies have cautiously suggested that problematic smartphone use is related to overuse as well as problems with social relationships and academic achievement., ${ }^{5,910}$ According to a South Korean study that surveyed smartphone dependency and health habits, exposure to harmful social media was associated with smoking, drinking, and the consumption of unhealthy food. ${ }^{11,12}$ Use duration and use for the purpose of communication are closely related to problematic smartphone use ${ }^{13}$ and health problems. A previous study reported that high-frequency users tended to be more sedentary than low-frequency users. ${ }^{14}$ Since smartphones might become a replacement for face-to-face interaction, ${ }^{15}$ adolescents who engage in excessive use may experience mental problems. ${ }^{12,16}$ Further, late-night use is associated with the risk of 
sleep disorders, ${ }^{17}$ and reduced sleep owing to smartphone use may lead to suicidal ideation and suicide plans. ${ }^{18}$

Adolescents are known to be desirous of social relationships, ${ }^{19}$ and smartphones facilitate social interactions that are not limited by space and time. ${ }^{20}$ Thus, this mode of communication is often an escape from solitude, which is likely to have negative effects on psychological well-being. ${ }^{21}$

According to a national cross-sectional study of South Korean adolescents, ${ }^{3}$ conflicts with surrounding people and poor academic record were associated with increased smartphone use. Concerns about smartphone use are a source of parentchild conflicts, ${ }^{22}$ and intimate social communication and reduced relationship satisfaction owing to smartphone use may be associated with smartphone dependency. ${ }^{23}$ In addition, according to the 2019 Korean national survey, conflicts with family or friends owing to smartphone use were associated with suicide attempts in adolescents. ${ }^{3}$ Excessive social media use (e.g., Facebook, YouTube) and cyberbullying through social networking services might increase the risk of problematic relationships, ${ }^{23,24}$ which may be a risk factor for poor sleep quality, stress, depression, and suicidal behaviors. In addition, adolescents who use smartphones excessively tend to engage in multitasking (e.g., using social media while studying and doing homework), which is likely to have a negative impact on their academic record. ${ }^{25}$ In a recent study, adolescents with low self-regulation ability were likely to experience academic problems because of their inability to refrain from smartphone use while studying. ${ }^{26}$ Academic achievement is an important stress factor for South Korean adolescents, ${ }^{27}$ and problematic smartphone use is associated with lower academic performance. ${ }^{28}$ Further, low academic achievement is correlated with inappropriate health behaviors, ${ }^{29}$ stress, and depression. ${ }^{30}$ Despite the possible association of problematic smartphone use with health outcomes, few studies have reported its relation to health behaviors and mental health status. In addition, there is a lack of high-quality studies (in terms of instruments, samples, etc.) on problematic smartphone use.

Considering the above, it is necessary to investigate the association of problematic smartphone use with unhealthy behaviors and mental health, and to obtain evidence that could help prevent adolescents from engaging in excessive smartphone use. Therefore, the purpose of this study, based on nationally representative data, is to investigate the associations between problematic smartphone use, unhealthy behaviors, and mental health in the South Korean adolescent population.

\section{METHODS}

\section{Data source}

The data were derived from the 2017 Korea Youth Risk Be- havior Survey (KYRBS) conducted by the Korea Centers for Disease Control and Prevention. The KYRBS employs a stratified, three-stage clustering design to produce a nationally representative sample of public and private middle and high school students. Launched in 2005, the KYRBS aims at obtaining 10,000 valid responses per school year (30,000 from middle school and 30,000 from high school) to achieve reliable statistical results for each geographic region. In this sample, 10,000 respondents were selected from each grade from middle to high school; thus, the sample size was taken as an effective sample for each grade. Based on this, the school sample size was set at 400 . One class was selected as the sample for each surveyed grade in the selected schools and 25 students were selected as the effective number of respondents in each extracted class (e.g., 400 middle school classes 1 st $\times 25$ responses $=10,000) .{ }^{29}$ The first stage involved 117 cities and districts with similar geographic locations. In the second stage, 400 middle schools and 400 high schools were selected from within the 117 cities and districts. The third stage of sampling involved randomly selecting one class from each grade from the selected schools. All students in the chosen classes were eligible to participate. Students used their certificate numbers to access and complete questionnaires anonymously during a regular class period. The KYRBS was officially approved by the Korea National Statistical Office (Certificate Number: 117058). Detailed information on the data source is available elsewhere. ${ }^{29}$ The overall response rate of the 13th KYRBS was $95.8 \%(62,276)$. Smartphone users were defined as those who answered yes to the question, "Have you used your own or someone else's smartphone in the last 30 days?" Finally, 54,603 adolescent smartphone users were selected as the study population. The variables were classified based on the KYRBS' health index for South Korean adolescents. ${ }^{16}$

\section{Problematic smartphone use-related characteristics}

Characteristics associated with problematic smartphone use included the number of hours spent using a smartphone on weekdays and weekends, the main purpose of smartphone use, conflicts with family and friends, and academic problems owing to smartphone use. Owing to a lack of relevant recommendations, our categorizations were based on previous studies addressing the relationship between smartphone use and health status or behavior in South Korean adolescents. Further, in general, South Korean students use smartphones more on weekends because they spend most of their time at school on weekdays. ${ }^{3,420}$ The number of hours spent using a smartphone was assessed by the following question: "During the weekdays of the last 30 days, for how many hours on average did you use a smartphone in one day?" and "During the weekends of the last 30 days, for how many hours on average did 
you use a smartphone in one day?" We classified responses into three groups: 1) Weekdays: $<2$ hours, $\geq 2$ hours and $<4$ hours, and $\geq 4$ hours; 2 ) Weekends: 4 hours, $\geq 4$ hours and $<8$ hours, and $\geq 8$ hours. The main purpose for using a smartphone was identified by the response to the question, "Please select the most frequently used smartphone service in the last 30 days." The response options were education (e.g., online lectures), searching for information, messaging/chatting (e.g., Line, My People, KakaoTalk), playing games, watching videos, watching cartoons, reading fiction, listening to music, watching user-created content (UCC; Afreeka TV, YouTube), going to a café, online communities, emailing, shopping, using social media (e.g., blogs, Instagram, Twitter, Facebook), and others; subjects could select only one option. We referenced the concepts proposed in previous studies ${ }^{3,13,20}$ and divided the main purpose for using a smartphone into three groups: 1) communication (messaging/chatting, going to an internet café or being part of an online community, emailing, and using social media); 2) enjoyment (playing games, watching videos, reading comics and fiction, listening to music, watching UCC, and shopping); and 3) education (searching for education-related information or studying).

The following prompts were used to assess severe conflicts with family and friends and academic problems owing to smartphone use. "In the last 30 days, I have had a severe conflict with my family owing to smartphone use," "In the last 30 days, I have had a severe conflict with my friends owing to smartphone use," and "In the last 30 days, I have had a study problem owing to smartphone use." Participants could choose between the following responses: strongly disagree, disagree, agree, and strongly agree. We defined "agree" and "strongly agree" as "yes" and the other responses as "no."

\section{Unhealthy behaviors}

Unhealthy behaviors included smoking, drinking, physical inactivity, skipping breakfast, and eating fast food. Those who had smoked and consumed alcohol at least once in the preceding 30 days were defined as smokers and drinkers, respectively. As for physical inactivity, we considered the most recent seven days on which the duration of exercise was under 20 minutes, the amount of time sufficient to increase heart rate or respiration. The unhealthy behavior variables were classified according to the indicators in Korea's National Health Plan 2020 and the 13th KYRBS guidelines ${ }^{31}$ : smoking (yes, no), drinking (yes, no), physical inactivity ( $<3$ days/week, $\geq 3$ days/week), ${ }^{32}$ skipping breakfast ( $<5$ times/week, $\geq 5$ times/ week), ${ }^{33}$ and eating fast food ( $<3$ times/week, $\geq 3$ times/week). ${ }^{33}$ These indicators were developed and reviewed by 15 academic advisory committees specialized in youth health-risk behaviors and a senior advisory committee representing aca- demic societies in Korea. ${ }^{31,34}$

\section{Mental health}

The assessment of mental health accounted for sleep disturbance, stress, depressive symptoms, suicidal ideation, and suicide attempts. Sleep disturbance was evaluated using the following question: "Was the amount of sleep you had in the past seven days sufficient for relieving fatigue?" Participants could choose between the following responses: completely sufficient, sufficient, moderate, not sufficient, or not at all sufficient. We defined "moderate, not sufficient and not at all sufficient" as "yes" and the other responses as "no." Stress was evaluated using the following question: "How would you rate your usual stress level?" Participants could choose between the following responses: very high, high, moderate, low, or none. Responses of "very high" and "high" indicated that the subjects had experienced stress while the other responses indicated that they had not. Depressive symptoms, suicidal ideation, and suicide attempts were assessed by the following questions: "During the past 12 months, did you ever feel so sad or hopeless almost every day for two weeks or more in a row that you stopped engaging in some usual activities?" "During the past 12 months, have you ever seriously thought of committing suicide?" and "During the past 12 months, have you ever attempted suicide?" Participants could choose between the following responses: "yes" or "no."

\section{Covariates}

General characteristics were used as covariates: gender, school year (middle school grades 1 to 3 , high school grades 1 to 3), perceived academic record (high, middle, low), family structure (living with parents, single parent, or others), parents' educational level ( $\geq$ college, high school, $\leq$ middle school, don't know/missing), perceived economic status (high, middle, low), and place of residence (large, small, or mediumsized city). Academic record and economic status were based on the subjects' individual perceptions.

\section{Statistical analysis}

Behaviors associated with smartphone use are presented as numbers and percentages. Problematic smartphone use, unhealthy behaviors, and mental health status were analyzed using chi-square tests. Multiple logistic regression analyses were performed to investigate the associations between problematic smartphone use, unhealthy behaviors, and mental health. We considered differences in covariance to clarify the effect of independent variables on dependent variables. Adjusted odds ratios (aORs) and 95\% confidence intervals (CIs) were derived from a series of logistic regression analyses after adjusting for gender, school year, perceived academic record, 
Table 1. Characteristics of subjects

\begin{tabular}{|c|c|c|c|}
\hline Characteristics & Total $(\mathrm{N}=54,603)$ & Boys $(\mathrm{n}=26,930)$ & Girls $(n=27,673)$ \\
\hline \multicolumn{4}{|l|}{ School year } \\
\hline Middle school 1st & $8,900(14.8)$ & $4,436(14.9)$ & $4,464(14.7)$ \\
\hline Middle school 2nd & $9,054(15.3)$ & $4,470(15.3)$ & $4,584(15.4)$ \\
\hline Middle school 3rd & $9,011(15.0)$ & $4,411(15.1)$ & $4,600(14.9)$ \\
\hline High school 1st & $8,960(17.2)$ & $4,355(17.3)$ & $4,605(17.2)$ \\
\hline High school 2nd & $9,506(19.1)$ & $4,768(19.0)$ & $4,738(19.1)$ \\
\hline High school 3rd & $9,172(18.6)$ & $4,490(18.5)$ & $4,682(18.8)$ \\
\hline \multicolumn{4}{|l|}{ Perceived academic record } \\
\hline Good & $21,913(39.8)$ & $11,169(41.3)$ & $10,744(38.3)$ \\
\hline Average & $15,707(28.9)$ & $7,439(27.7)$ & $8,268(30.1)$ \\
\hline Poor & $16,983(31.3)$ & $8,322(30.9)$ & $8,661(31.6)$ \\
\hline \multicolumn{4}{|l|}{ Family structure } \\
\hline Lives with both parents & $44,964(83.2)$ & $22,116(82.9)$ & $22,848(83.5)$ \\
\hline Lives with father & $2,524(4.3)$ & $1,374(4.8)$ & $1,150(3.8)$ \\
\hline Lives with mother & $5,634(10.1)$ & $2,650(9.7)$ & $2,984(10.5)$ \\
\hline Lives with others & $1,481(2.5)$ & $790(2.7)$ & $691(2.3)$ \\
\hline \multicolumn{4}{|l|}{ Parental educational level } \\
\hline$\geq$ College & $31,987(60.1)$ & $15,649(59.7)$ & $16,338(60.4)$ \\
\hline High school & $12,113(21.9)$ & $5,730(21.0)$ & $6,383(23.0)$ \\
\hline$\leq$ Middle school & $386(0.6)$ & $174(0.6)$ & $212(0.7)$ \\
\hline Don't know/missing & $10,117(17.3)$ & $5,377(18.8)$ & $4,740(15.9)$ \\
\hline \multicolumn{4}{|l|}{ Perceived economic status } \\
\hline High & $21,519(39.9)$ & $11,449(42.9)$ & $10,070(36.9)$ \\
\hline Middle & $25,297(46.0)$ & $11,785(43.5)$ & $13,512(48.5)$ \\
\hline Low & $7,787(14.1)$ & $3,696(13.6)$ & $4,091(14.5)$ \\
\hline \multicolumn{4}{|l|}{ Place of residence } \\
\hline Large city & $24,391(43.4)$ & $11,676(43.3)$ & $12,715(43.5)$ \\
\hline Small or medium-sized city & $26,025(50.6)$ & $13,122(50.8)$ & $12,903(50.3)$ \\
\hline Town & $4,187(6.0)$ & $2,132(5.9)$ & $2,055(6.2)$ \\
\hline \multicolumn{4}{|c|}{ Mean time of smartphone use per weekday (hours) } \\
\hline$<2$ & $14,542(26.7)$ & $8,651(31.8)$ & $5,891(21.5)$ \\
\hline$>2,<4$ & $22,710(42.0)$ & $11,168(42.0)$ & $11,542(42.0)$ \\
\hline$\geq 4$ & $17,351(31.3)$ & $7,111(26.2)$ & $10,240(36.5)$ \\
\hline \multicolumn{4}{|c|}{ Mean time of smartphone use per day during weekends (hours) } \\
\hline$<4$ & $20,561(38.7)$ & $12,395(46.8)$ & $8,166(30.3)$ \\
\hline$>4,<8$ & $21,494(39.5)$ & $9,944(36.9)$ & $11,550(42.2)$ \\
\hline$\geq 8$ & $12,548(21.8)$ & $4,591(16.3)$ & $7,957(27.5)$ \\
\hline \multicolumn{4}{|l|}{ Main purpose for using a smartphone } \\
\hline Communication & $25,740(46.9)$ & $8,931(33.6)$ & $16,809(60.5)$ \\
\hline Enjoyment & $24,661(44.9)$ & $15,356(56.0)$ & $9,305(33.5)$ \\
\hline Education & $4,202(8.2)$ & $2,643(10.4)$ & $1,559(6.0)$ \\
\hline \multicolumn{4}{|c|}{ Severe conflicts with family owing to smartphone use } \\
\hline No & $42,602(77.7)$ & $21,551(79.6)$ & $21,051(75.7)$ \\
\hline Yes & $12,001(22.3)$ & $5,379(20.4)$ & $6,622(24.3)$ \\
\hline
\end{tabular}


Table 1. Characteristics of subjects (continued)

\begin{tabular}{lcrc}
\hline \multicolumn{1}{c}{ Characteristics } & Total $(\mathrm{N}=54,603)$ & Boys $(\mathrm{n}=26,930)$ & Girls $(\mathrm{n}=27,673)$ \\
\hline Severe conflicts with friends owing to smartphone use & & & \\
$\quad$ No & $41,130(74.2)$ & $21,764(79.7)$ & $19,366(68.4)$ \\
Yes & $13,473(25.8)$ & $5,166(20.3)$ & $8,307(31.6)$ \\
Academic problems owing to smartphone use & & & \\
$\quad$ No & $52,704(96.6)$ & $26,154(97.1)$ & $26,550(96.0)$ \\
$\quad$ Yes & $1,899(3.4)$ & $776(2.9)$ & $1,123(4.0)$ \\
\hline
\end{tabular}

Data are expressed as numbers and percentages (\%)

family structure, parental educational level, perceived economic status, and place of residence. The data were analyzed using IBM SPSS Statistics for Windows, version 24 (IBM Corp., Armonk, NY, USA). The process utilized a complex sample analysis module considering stratification variables, cluster variables, and weights. P-values lower than 0.05 were considered statistically significant.

\section{RESULTS}

When differentiating between weekdays and weekends, $31.3 \%$ and $61.3 \%$ of the subjects, respectively, used smartphones for more than four hours. The time spent using smartphones for communication (46.9\%) was greater than that spent on use for educational purposes (44.9\%) and enjoyment (44.9\%). Of the sample, $22.3 \%$ experienced severe conflicts with family, $25.8 \%$ experienced severe conflicts with friends, and 3.4\% experienced academic problems (Table 1).

The longer the duration of smartphone use, the greater was the likelihood of reporting unhealthy behaviors and poor mental health. However, smartphone use did not display such an association with physical inactivity. Compared to adolescents who used smartphones for educational purposes, those who used them for communication were more likely to report smoking $(\mathrm{aOR}=2.63,95 \% \mathrm{CI}=2.25-3.07)$, drinking $(\mathrm{aOR}=$ 2.27, 95\% CI=2.05-2.52), and fast food consumption $(\mathrm{aOR}=$ $1.37,95 \% \mathrm{CI}=1.25-1.50)$. Further, smartphone use for communication purposes was associated with increased risk of sleep disturbance $(\mathrm{aOR}=1.36,95 \% \mathrm{CI}=1.26-1.47)$, depressive symptoms ( $\mathrm{aOR}=1.17,95 \% \mathrm{CI}=1.08-1.27)$, and suicidal ideation (aOR=1.05 95\% CI=0.93-1.19) (Table 2). Gender-stratified analyses are presented in Supplementary Table 1 (in the online-only Data Supplement).

Adolescents who experienced severe conflicts with family and friends were more likely to smoke, drink, and have poor mental health. Adolescents with academic problems were more likely to smoke ( $\mathrm{aOR}=3.49,95 \% \mathrm{CI}=2.99-4.10)$ and drink ( $\mathrm{aOR}=2.37,95 \% \mathrm{CI}=2.12-2.64)$ and experience stress $(\mathrm{aOR}=2.33,95 \% \mathrm{CI}=2.11-2.57)$, suicidal ideation $(\mathrm{aOR}=1.42$,
95\% CI $1.25-1.62)$, and suicide attempts ( $\mathrm{aOR}=1.89,95 \% \mathrm{CI}=$ $1.55-2.30$ ) than adolescents without academic problems ( $\mathrm{Ta}-$ ble 3). Gender-stratified analyses are presented in Supplementary Table 2 (in the online-only Data Supplement).

\section{DISCUSSION}

The purpose of this study was to investigate the relationships between problematic smartphone use, unhealthy behaviors, and mental health among South Korean adolescents. According to the results, a longer duration of smartphone use and usage for communication purposes were associated with unhealthy behaviors and poor mental health. Severe conflicts with family and friends and academic problems owing to smartphone use were also associated with unhealthy behaviors and mental health.

In this sample, approximately $30 \%$ of adolescents used their smartphones for more than four hours on weekdays, while this proportion stood at $60 \%$ on weekends. Since there are not many leisure activities South Korean adolescents may engage in, they spend time on their easy-to-use smartphones. ${ }^{35}$ In previous studies of South Korean adolescents, 50\% reported use more than three hours, ${ }^{3} 40 \%$ reported use more than four hours. ${ }^{36}$ Regarding other nationalities, approximately $10 \%$ of Japanese adolescents ${ }^{16}$ and $20 \%$ of Swiss young adults ${ }^{37}$ reported use more than five hours a day. Usage duration may differ depending on the research method or social environment (e.g., smartphone penetration and internet access speed ${ }^{26}$ ).

More than $30 \%$ of adolescents experienced conflicts with parents or friends, and 3.4\% experienced academic problems. As per a previous study, strict parenting, poor friendships, and academic failure owing to low self-control were the most important risk factors for problematic smartphone use in adolescents. ${ }^{5}$ A South Korean study reported that smartphone addiction was associated with dysfunction and poor interaction with peers. ${ }^{23}$ South Korean adolescents experience high levels of academic pressure; in this situation, smartphones are a way to relieve stress. ${ }^{13}$ Previous studies have established that adolescents' relationship and academic problems may be risk 


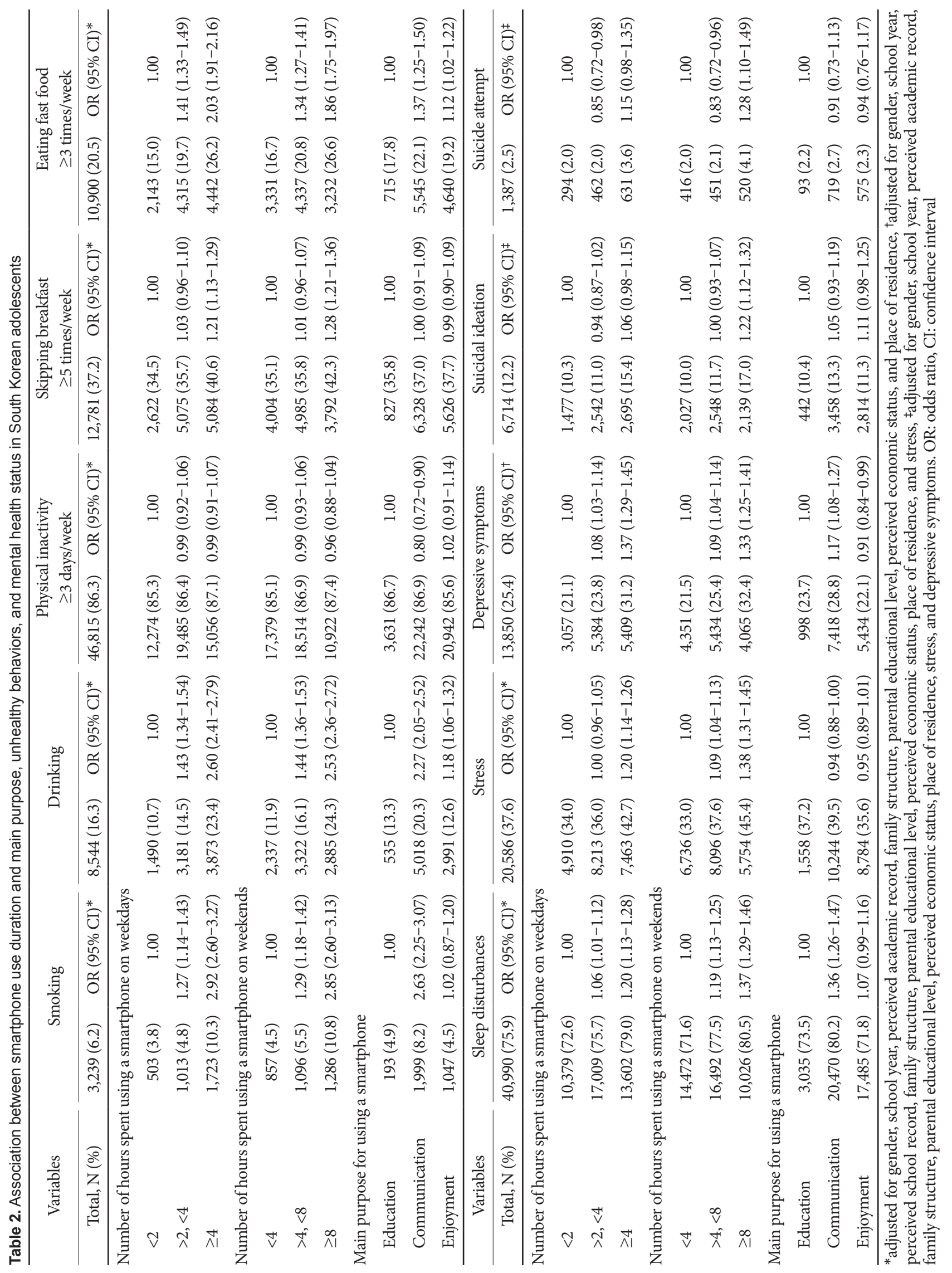




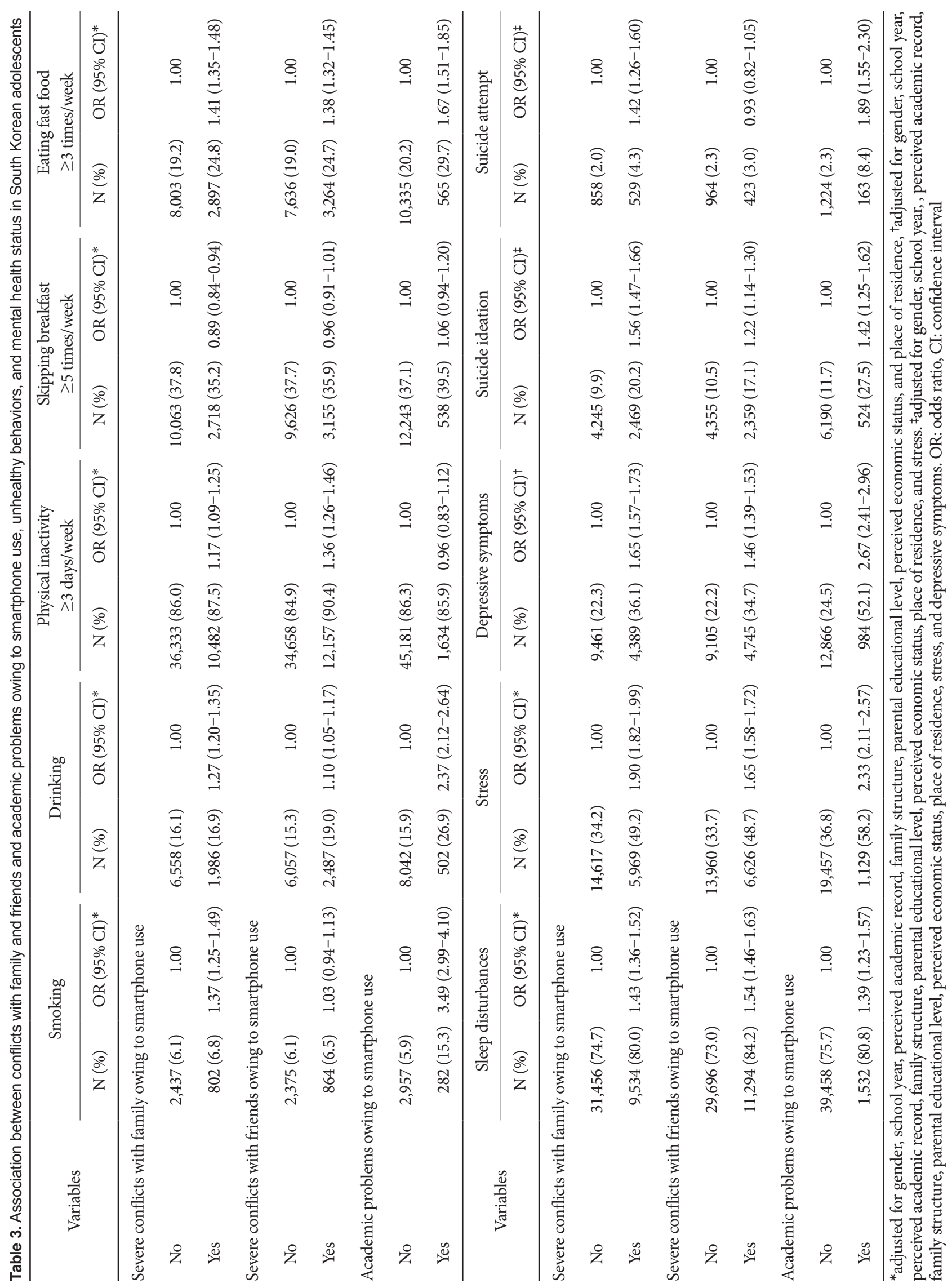


factors for problematic smartphone use, and our results may be understood within this context.

Consistent with previous studies, ${ }^{3,35,38,39}$ a longer duration of smartphone use and usage for communication purposes were associated with unhealthy behaviors and poor mental health status. Further, as with some other studies, ${ }^{14,40}$ problematic smartphone use was not associated with physical inactivity. A possible explanation is that adolescnet might use smartphones while engaging in low-intensity exercise for relatively long periods, which might contribute to health and fitness. ${ }^{41}$ Further studies are required to better understand the relationship between smartphone use and intensity of physical activity. Adolescents accustomed to the digital media stimulation afforded by smartphones could be frequently exposed to alcohol and tobacco. ${ }^{42}$ In South Korean adolescents, the main reason for smoking and drinking has been reported to be the satisfaction of having social relationships. ${ }^{43}$ Our findings indicated that increased smoking and drinking were associated with using smartphones for communication. In a Chinese study of young adults and a Japanese study on adolescents, ${ }^{12,16}$ excessive smartphone usage for communication, such as social networking services and online chatting, was associated with sleep disorders, stress, and depression. Therefore, smartphone use for relationship formation and maintenance is likely to have harmful effects on the mental development of adolescents.

Severe conflicts with parents and friends and academic problems owing to smartphone use were associated with poor health status. In previous studies, low-quality relationships with both mothers and fathers were associated with a greater likelihood of fast food consumption, insufficient sleep ${ }^{44}$ unhealthy food-related behaviors, ${ }^{45}$ and negative relationships with parents and friends, which, in turn, increased the possibility of depression ${ }^{46}$ and suicide. ${ }^{3}$ According to a recent study, higher problematic social media use was associated with cyberbullying, which exposed adolescents to psychosocial risks. ${ }^{47}$ Adolescents with lower GPAs have been reported to be associated with poor mental health and behavior problems. ${ }^{48}$ Preventing conflicts with family and friends and academic problems could help reduce the risk of problematic smartphone use among adolescents. This study has several limitations. First, all information of KYRBS, including smartphone use time, were collected by self-reported measure. In previous studies, adolescents were more likely to report shorter durations compared to their actual use time by timestamp reporting application. ${ }^{49,50}$ Therefore, smartphone use time of our study might be underestimated, and objective measure by technology instruments may be sensitive. ${ }^{51,52}$ Second, there is a lack of sufficient investigating studies which problematic smartphone use related classification criteria or guidelines, ${ }^{53}$ therefore, we classified the smartphone usage time according to previous studies. This suggests that health-related results may vary depending on the criteria employed for the classification of usage time. Further, there is a need for studies presenting scientific evidence for the determination of a cutoff value that may be used to predict health problems resulting from problematic smartphone use. Third, the use of crosssectional survey data did not allow us to elucidate temporal relationships or draw inferences regarding causality. The relationship between problematic smartphone use and poor mental health may involve reverse causation. ${ }^{39}$ For example, adolescents with depression, anxiety, and attention-deficit hyperactivity disorder may be more prone to excessive smartphone use. ${ }^{28}$ Therefore, we emphasize the need for additional longitudinal studies to evaluate the causal relationships between smartphone use, unhealthy behaviors, and mental health status. Fourth, this study used self-reported questionnaires, which may be affected by social desirability and response biases. For example, adolescents might have sought to answer the questions regarding smoking and drinking in the most socially acceptable manner, leading to inaccurate reporting. Fourth, owing to the use of multiple comparisons, the possibility of chance in the results cannot be excluded. Finally, mental health variables were measured subjectively, using simple questions rather than standardized tools. Therefore, to obtain objective data on these variables, it is necessary to use standardized assessment scales and diagnostic interviews conducted by professionals.

Despite its limitations, the advantages of this study are as follows. The key strength of this study, based on a governmentapproved nationally representative data set, is that it offers the necessary insight to make relevant predictions regarding the risks of problematic smartphone use. Further, the findings may be generalized to all South Korean adolescents. Most previous studies have measured the level of smartphone addiction to determine the relationships between influential factors and the addiction itself. In this study, however, we investigated real smartphone use-related problems experienced by adolescents and tried to clarify the relationships between problematic smartphone use, unhealthy behaviors, and mental health.

\section{Supplementary Materials}

The online-only Data Supplement is available with this article at https://doi.org/10.30773/pi.2020.0007.

\section{Acknowledgments}

None.

\section{Conflicts of Interest}

The authors have no potential conflicts of interest to disclose.

\section{Author Contributions}

Conceptualization: Hae Ran Kim, Mi Ah Han. Data curation: Hae Ran 
Kim, Mi Ah Han. Formal analysis: Hae Ran Kim, Mi Ah Han. Investigation: Hae Ran Kim, Mi Ah Han. Methodology: Hae Ran Kim, Mi Ah Han. Project administration: Hae Ran Kim, Mi Ah Han. Resources: Hae Ran Kim, Mi Ah Han. Software: Hae Ran Kim, Mi Ah Han. Supervision: Mi Ah Han. Validation: Hae Ran Kim, Mi Ah Han. Visualization: Hae Ran Kim, Mi Ah Han. Writing_original draft: Hae Ran Kim. Writing_review \& editing: Hae Ran Kim, Mi Ah Han.

\section{ORCID iDs}

\section{Hae Ran Kim}

Mi Ah Han https://orcid.org/0000-0001-7961-3851

https://orcid.org/0000-0003-1213-6952

\section{REFERENCES}

1. Lo Coco G, Salerno L, Franchina V, La Tona A, Di Blasi M, Giordano C. Examining bi-directionality between Fear of Missing Out and problematic smartphone use. A two-wave panel study among adolescents. Addict Behav 2020;106:106360.

2. Korea Internet and Security Agency. 2017 Survey on Internet Usage. 2018. Available at: https://isis.kisa.or.kr/board/?pageId $=060100$. Accessed October 2, 2019.

3. Kim MH, Min SH, Ahn JS, An CS, Lee JH. Association between high adolescent smartphone use and academic impairment, conflicts with family members or friends, and suicide attempts. PLoS One 2019;14: e0219831.

4. Bae SM. The relationship between the type of smartphone use and smartphone dependence of Korean adolescents: National survey study. Child Youth Serv Rev 2017;81:207-211.

5. Fischer-Grote L, Kothgassner OD, Felnhofer A. Risk factors for problematic smartphone use in children and adolescents: a review of existing literature. Neuropsychiatr 2019;33:179-190.

6. Jo HS, Na EH, Kim DJ. The relationship between smartphone addiction predisposition and impulsivity among Korean smartphone users. Addict Res Theory 2018;26:77-84

7. Extremera N, Quintana-Orts C, Sánchez-Álvarez N, Rey L. The role of cognitive emotion regulation strategies on problematic smartphone use: Comparison between problematic and non-problematic adolescent users. Int J Environ Res Public Health 2019;16:3142.

8. Long J, Liu TQ, Liao YH, Qi C, He HY, Chen SB, et al. Prevalence and correlates of problematic smartphone use in a large random sample of Chinese undergraduates. BMC Psychiatry 2016;16:408.

9. Cho YG. Excessive and problematic smartphone use and poor mental health in adolescents. Korean J Fam Med 2020;41:73-74.

10. Lee HN, Kim JH. A structural equation model on Korean adolescents' excessive use of smartphones. Asian Nurs Res (Korean Soc Nurs Sci) 2018;12:91-98.

11. Lim HS, Kim SK. Analysis of health habit and hair mineral nutrition status of media addicted adolescent. J Nutr Health 2018;51:295-306.

12. Chen B, Liu F, Ding S, Ying X, Wang L, Wen Y. Gender differences in factors associated with smartphone addiction: a cross-sectional study among medical college students. BMC Psychiatry 2017;17:341.

13. Cha SS, Seo BK. Smartphone use and smartphone addiction in middle school students in Korea: prevalence, social networking service, and game use. Health Psychol Open 2018;5:2055102918755046.

14. Barkley JE, Lepp A. Mobile phone use among college students is a sedentary leisure behavior which may interfere with exercise. Comput $\mathrm{Hu}-$ man Behav 2016;56:29-33.

15. Dwyer RJ, Kushlev K, Dunn EW. Smartphone use undermines enjoyment of face-to-face social interactions. J Exp Soc Psychol 2018;78:233239.

16. Tamura H, Nishida T, Tsuji A, Sakakibara H. Association between excessive use of mobile phone and insomnia and depression among Japanese adolescents. Int J Environ Res Public Health 2017;14.

17. Hysing M, Pallesen S, Stormark KM, Jakobsen R, Lundervold AJ, Sivertsen B. Sleep and use of electronic devices in adolescence: results from a large population-based study. BMJ Open 2015;5:e006748.

18. Jeong WJ, Kim YK, Lee HJ, Jang JE, Kim Sl, Park EC, et al. Association of bedtime with both suicidal ideation and suicide planning among Korean adolescents. Int J Environ Res Public Health 2019;16:3817.

19. Maurizi LK, Grogan-Kaylor A, Granillo MT, Delva J. The role of social relationships in the association between adolescents' depressive symptoms and academic achievement. Child Youth Serv Rev 2013;35:618625 .

20. Lee HU, Kim JW, Choi TY. Risk factors for smartphone addiction in Korean adolescents: smartphone use patterns. J Korean Med Sci 2017; 32:1674-1679.

21. Bozzola E, Spina G, Ruggiero M, Vecchio D, Caruso C, Bozzola M, et al. Media use during adolescence: the recommendations of the Italian Pediatric Society. Ital J Pediatr 2019;45:149.

22. Radesky JS, Eisenberg S, Kistin CJ, Gross J, Block G, Zuckerman B, et al. Overstimulated consumers or next-generation learners? Parent tensions about child mobile technology use. Ann Fam Med 2016;14:503508.

23. Kim HJ, Min JY, Min KB, Lee TJ, Yoo SH. Relationship among family environment, self-control, friendship quality, and adolescents' smartphone addiction in South Korea: Findings from nationwide data. PLoS One 2018;13:e0190896.

24. Zheng X, Lee MKO. Excessive use of mobile social networking sites: Negative consequences on individuals. Comput Human Behav 2016;65: 65-76.

25. Rosen LD, Mark Carrier L, Cheever NA. Facebook and texting made me do it: Media-induced task-switching while studying. Comput $\mathrm{Hu}-$ man Behav 2013;29:948-958.

26. Winskel H, Kim TH, Kardash L, Belic I. Smartphone use and study behavior: a Korean and Australian comparison. Heliyon 2019;5:e02158.

27. Park SB, Jang HS, Lee ES. Major stressors among Korean adolescents according to gender, educational level, residential area, and socioeconomic status. Int J Environ Res Public Health 2018;15:2080.

28. Grant JE, Lust K, Chamberlain SR. Problematic smartphone use associated with greater alcohol consumption, mental health issues, poorer academic performance, and impulsivity. J Behav Addict 2019;8:335-342.

29. Kim SY, Sim SY, Park BJ, Kong IG, Kim JH, Choi HG. Dietary habits are associated with school performance in adolescents. Medicine (Baltimore) 2016;95:e3096.

30. Park MJ, Choi JH, Lim SJ. Factors affecting aggression in south Korean middle school students. Asian Nurs Res (Korean Soc Nurs Sci) 2014;8: 247-253.

31. Kim YJ, Choi SH, Chun CM, Park SY, Khang YH, Oh KW. Data resource profile: The Korea Youth Risk Behavior Web-based Survey (KYRBS). Int J Epidemiol 2016;45:1076e.

32. Lee CG, Park SY, Lee SH, Kim HW, Park JW. Social cognitive theory and physical activity among Korean male high-school students. Am J Mens Health 2018;12:973-980.

33. Park SB, Rim SJ, Lee JH. Associations between dietary behaviours and perceived physical and mental health status among Korean adolescents. Nutr Diet 2018;75:488-493.

34. Bae JS, Joung Hj, Kim JY, Kwon KN, Kim YT, Park SW. Test-retest reliability of a questionnaire for the Korea Youth Risk Behavior Web-based Survey. J Prev Med Public Health 2010;43:403-410.

35. Kim SG, Park J, Kim HT, Pan Z, Lee Y, McIntyre RS. The relationship between smartphone addiction and symptoms of depression, anxiety, and attention-deficit/hyperactivity in South Korean adolescents. Ann Gen Psychiatry 2019;18:1.

36. Lee KE, Kim SH, Ha TY, Yoo YM, Han JJ, Jung JH, et al. Dependency on smartphone use and its association with anxiety in Korea. Public Health Rep 2016;131:411-419.

37. Haug S, Castro RP, Kwon M, Filler A, Kowatsch T, Schaub MP. Smartphone use and smartphone addiction among young people in Switzerland. J Behav Addict 2015;4:299-307.

38. Matar Boumosleh J, Jaalouk D. Depression, anxiety, and smartphone 
addiction in university students-A cross sectional study. PLoS One 2017; 12:e0182239.

39. Jun SM. The reciprocal longitudinal relationships between mobile phone addiction and depressive symptoms among Korean adolescents. Comput Human Behav 2016;58:179-186.

40. Fennell C, Barkley JE, Lepp A. The relationship between cell phone use, physical activity, and sedentary behavior in adults aged 18-80. Comput Human Behav 2019;90:53-59.

41. Rebold MJ, Sheehan T, Dirlam M, Maldonado T, O'Donnell D. The impact of cell phone texting on the amount of time spent exercising at different intensities. Comput Human Behav 2016;55:167-171.

42. Romer D, Moreno M. Digital media and risks for adolescent substance abuse and problematic gambling. Pediatrics 2017;140:S102-S106.

43. Kye SY, Kwon JH, Park K. Happiness and health behaviors in South Korean adolescents: a cross-sectional study. Epidemiol Health 2016;38: e2016022.

44. Blewitt C, Bergmeier H, Macdonald JA, Olsson CA, Skouteris H. Associations between parent-child relationship quality and obesogenic risk in adolescence: a systematic review of recent literature. Obes Rev 2016; 17:612-622.

45. Martin-Biggers J, Quick V, Zhang M, Jin Y, Byrd-Bredbenner C. Relationships of family conflict, cohesion, and chaos in the home environment on maternal and child food-related behaviours. Matern Child Nutr 2018;14:e12540.

46. Zhang S, Baams L, van de Bongardt D, Dubas JS. Intra- and inter-indi- vidual differences in adolescent depressive mood: the role of relationships with parents and friends. J Abnorm Child Psychol 2018;46:811824.

47. Kircaburun K, Kokkinos CM, Demetrovics Z, Király O, Griffiths MD, Çolak TS. Problematic online behaviors among adolescents and emerging adults: associations between cyberbullying perpetration, problematic social media use, and psychosocial factors. Int J Ment Health Addict 2019;17:891-908.

48. McLeod JD, Uemura R, Rohrman S. Adolescent mental health, behavior problems, and academic achievement. J Health Soc Behav 2012;53: 482-497.

49. Andrews S, Ellis DA, Shaw H, Piwek L. Beyond self-report: tools to compare estimated and real-world smartphone use. PLoS One 2015;10: e0139004.

50. Wilcockson TDW, Ellis DA, Shaw H. Determining typical smartphone usage: what data do we need? Cyberpsychol Behav Soc Netw 2018;21: 395-398.

51. Twenge JM, Campbell WK. Associations between screen time and lower psychological well-being among children and adolescents: evidence from a population-based study. Prev Med Rep 2018;12:271-283.

52. Lin YH, Lin YC, Lee YH, Lin PH, Lin SH, Chang LR, et al. Time distortion associated with smartphone addiction: identifying smartphone addiction via a mobile application (App). J Psychiatr Res 2015;65:139-145.

53. Harris B, Regan T, Schueler J, Fields SA. Problematic mobile phone and smartphone use scales: a systematic review. Front Psychol 2020;11: 672. 
Supplementary Table 1-1. Association between smartphone use duration and main purpose, unhealthy behaviors, and mental health status among boys

\begin{tabular}{|c|c|c|c|c|c|c|c|c|c|c|}
\hline \multirow{2}{*}{$\begin{array}{c}\text { Variables } \\
\text { Total, N (\%) }\end{array}$} & \multicolumn{2}{|c|}{ Smoking } & \multicolumn{2}{|c|}{ Drinking } & \multicolumn{2}{|c|}{ Physical inactivity $\geq 3$ days/week } & \multicolumn{2}{|c|}{ Skipping breakfast $\geq 5$ times/week } & \multicolumn{2}{|c|}{ Eating fast food $\geq 3$ times/week } \\
\hline & $2,428(9.4)$ & OR $(95 \% \mathrm{CI})^{*}$ & $4,835(18.6)$ & OR $(95 \% \mathrm{CI})^{*}$ & $21,348(80.1)$ & OR $(95 \% \mathrm{CI})^{*}$ & $6,129(22.7)$ & OR $(95 \% \mathrm{CI})^{*}$ & $5,652(21.5)$ & OR $(95 \% \mathrm{CI})^{*}$ \\
\hline \multicolumn{11}{|c|}{ Number of hours spent using a smartphone on weekdays } \\
\hline$<2$ & $424(5.3)$ & 1.00 & $1,077(12.9)$ & 1.00 & $6,844(80.2)$ & 1.00 & $1,596(18.4)$ & 1.00 & $1,403(16.4)$ & 1.00 \\
\hline$>2,<4$ & $835(7.9)$ & $1.38(1.21-1.58)$ & $1,887(17.5)$ & $1.36(1.24-1.50)$ & $8,865(80.2)$ & $0.99(0.92-1.08)$ & $2,538(22.7)$ & $1.21(1.11-1.31)$ & $2,286(21.2)$ & $1.37(1.27-1.48)$ \\
\hline$\geq 4$ & $1,169(16.8)$ & $2.82(2.45-3.23)$ & $1,871(27.1)$ & $2.25(2.02-2.50)$ & $5,639(80.0)$ & $0.98(0.89-1.07)$ & $1,995(28.0)$ & $1.46(1.33-1.60)$ & $1,963(28.2)$ & $1.97(1.80-2.15)$ \\
\hline \multicolumn{11}{|c|}{ Number of hours spent using a smartphone on weekends } \\
\hline$<4$ & $726(6.3)$ & 1.00 & $1,681(14.1)$ & 1.00 & $9,879(80.4)$ & 1.00 & $2,475(19.9)$ & 1.00 & $2,218(18.4)$ & 1.00 \\
\hline$>4,<8$ & $876(9.4)$ & $1.38(1.24-1.53)$ & $1,887(19.7)$ & $1.42(1.31-1.53)$ & $7,841(80.0)$ & $0.96(0.90-1.04)$ & $2,353(23.7)$ & $1.16(1.08-1.25)$ & $2,177(22.6)$ & $1.28(1.19-1.38)$ \\
\hline$\geq 8$ & $826(18.6)$ & $2.76(2.46-3.09)$ & $1,267(28.8)$ & $2.27(2.05-2.52)$ & $3,628(79.8)$ & $0.96(0.87-1.06)$ & $1,301(28.7)$ & $1.38(1.26-1.51)$ & $1,257(28.2)$ & $1.71(1.55-1.88)$ \\
\hline \multicolumn{11}{|c|}{ Main purpose for using a smartphone } \\
\hline Education & $161(6.5)$ & 1.00 & $396(15.6)$ & 1.00 & $2,175(82.6)$ & 1.00 & $518(19.6)$ & 1.00 & $483(19.4)$ & 1.00 \\
\hline Communication & $1,357(15.7)$ & $2.76(2.29-3.33)$ & $2,319(26.7)$ & $2.21(1.94-2.51)$ & $6,794(77.2)$ & $0.76(0.67-0.86)$ & $2,091(23.4)$ & $1.15(1.02-1.29)$ & $2,176(25.1)$ & $1.37(1.21-1.55)$ \\
\hline Enjoyment & $910(6.2)$ & $1.09(0.91-1.32)$ & $2,120(14.2)$ & $1.13(0.99-1.29)$ & $12,379(81.4)$ & $1.04(0.92-1.18)$ & $3,520(22.9)$ & $1.09(0.97-1.22)$ & $2,993(19.8)$ & $1.05(0.93-1.19)$ \\
\hline Variables & \multicolumn{2}{|c|}{ Sleep disturbances } & \multicolumn{2}{|c|}{ Stress } & \multicolumn{2}{|c|}{ Depressive symptoms } & \multicolumn{2}{|c|}{ Suicidal ideation } & \multicolumn{2}{|c|}{ Suicide attempt } \\
\hline Total, N (\%) & $18,549(70.1)$ & OR $(95 \% \mathrm{CI})^{*}$ & $8,146(30.5)$ & OR $(95 \% \mathrm{CI})^{*}$ & $5,426(20.4)$ & $\mathrm{OR}(95 \% \mathrm{CI})^{\dagger}$ & $2,500(9.3)$ & $\mathrm{OR}(95 \% \mathrm{CI})^{\ddagger}$ & $499(1.8)$ & $\mathrm{OR}(95 \% \mathrm{CI})^{\ddagger}$ \\
\hline \multicolumn{11}{|c|}{ Number of hours spent using a smartphone on weekdays } \\
\hline$<2$ & $5,761(68.1)$ & 1.00 & $2,456(28.8)$ & 1.00 & $1,566(18.3)$ & 1.00 & $718(8.5)$ & 1.00 & $145(1.7)$ & 1.00 \\
\hline$>2,<4$ & $7732(70.3)$ & $1.06(0.99-1.13)$ & $3,267(29.5)$ & $1.00(0.93-1.07)$ & $2,152(19.7)$ & $1.06(0.98-1.15)$ & $994(8.9)$ & $1.00(0.89-1.11)$ & $175(1.5)$ & $0.86(0.67-1.11)$ \\
\hline$\geq 4$ & $5,056(72.1)$ & $1.11(1.02-1.21)$ & $2,423(34.1)$ & $1.16(1.07-1.26)$ & $1,708(24.1)$ & $1.25(1.13-1.37)$ & $788(11.0)$ & $1.10(0.97-1.25)$ & $179(2.5)$ & $1.26(0.96-1.65)$ \\
\hline \multicolumn{11}{|c|}{ Number of hours spent using a smartphone on weekends } \\
\hline$<4$ & $8,164(67.2)$ & 1.00 & $3,420(28.0)$ & 1.00 & $2,265(18.7)$ & 1.00 & $1,029(8.4)$ & 1.00 & $219(1.7)$ & 1.00 \\
\hline$>4,<8$ & $7,065(72.2)$ & $1.20(1.13-1.28)$ & $3,023(30.5)$ & $1.08(1.01-1.16)$ & $2,003(20.4)$ & $1.03(0.96-1.11)$ & $916(9.1)$ & $0.98(0.89-1.09)$ & $153(1.5)$ & $0.82(0.65-1.04)$ \\
\hline$\geq 8$ & $3,320(73.5)$ & $1.27(1.16-1.40)$ & $1,703(37.3)$ & $1.42(1.30-1.54)$ & $1,158(25.3)$ & $1.21(1.09-1.34)$ & $555(12.4)$ & $1.20(1.05-1.38)$ & $127(2.9)$ & $1.30(0.99-1.72)$ \\
\hline \multicolumn{11}{|c|}{ Main purpose for using a smartphone } \\
\hline Education & $1,833(70.8)$ & 1.00 & $846(32.1)$ & 1.00 & $557(20.8)$ & 1.00 & $237(8.8)$ & 1.00 & $51(1.9)$ & 1.00 \\
\hline Communication & $6,613(74.9)$ & $1.30(1.17-1.44)$ & $2,695(30.4)$ & $0.92(0.84-1.01)$ & $2,097(23.8)$ & $1.20(1.06-1.35)$ & $884(10.0)$ & $1.12(0.94-1.33)$ & $175(2.0)$ & $1.00(0.70-1.42)$ \\
\hline Enjoyment & $10,103(67.0)$ & $0.99(0.90-1.10)$ & $4,605(30.2)$ & $0.93(0.85-1.02)$ & $2,772(18.3)$ & $0.87(0.77-0.98)$ & $1,379(9.0)$ & $1.02(0.97-1.20)$ & $273(1.8)$ & $0.87(0.62-1.22)$ \\
\hline
\end{tabular}

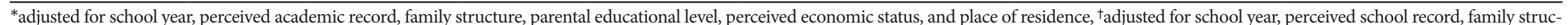

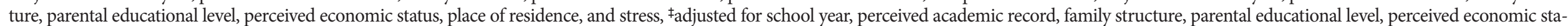
tus, place of residence, stress, and depressive symptoms. OR: odds ratio; CI: confidence interval 
Supplementary Table 1-2. Association between smartphone use duration and main purpose, unhealthy behaviors, and mental health status among girls

\begin{tabular}{|c|c|c|c|c|c|c|c|c|c|c|}
\hline \multirow{2}{*}{$\begin{array}{c}\text { Variables } \\
\text { Total, N (\%) } \\
\end{array}$} & \multicolumn{2}{|c|}{ Smoking } & \multicolumn{2}{|c|}{ Drinking } & \multicolumn{2}{|c|}{ Physical inactivity $\geq 3$ days/week } & \multicolumn{2}{|c|}{ Skipping breakfast $\geq 5$ times/week } & \multicolumn{2}{|c|}{ Eating fast food $\geq 3$ times/week } \\
\hline & $811(3.0)$ & OR $(95 \% \mathrm{CI})^{*}$ & $3,709(13.9)$ & OR $(95 \% \mathrm{CI})^{*}$ & $25,467(92.6)$ & OR $(95 \% \mathrm{CI})^{*}$ & $6,652(24.1)$ & OR $(95 \% \mathrm{CI})^{*}$ & $5,248(19.4)$ & OR $(95 \% \mathrm{CI})^{*}$ \\
\hline \multicolumn{11}{|c|}{ Number of hours spent using a smartphone on weekdays } \\
\hline$<2$ & $79(1.4)$ & 1.00 & $413(7.3)$ & 1.00 & $5,430(93.1)$ & 1.00 & $1,026(17.4)$ & 1.00 & $740(12.8)$ & 1.00 \\
\hline$>2,<4$ & $178(1.6)$ & $0.99(0.73-1.34)$ & $1,294(11.5)$ & $1.64(1.44-1.87)$ & $10,620(92.6)$ & $0.96(0.84-1.09)$ & $2,537(22.1)$ & $1.25(1.14-1.38)$ & $2,029(18.2)$ & $1.49(1.35-1.65)$ \\
\hline$\geq 4$ & $554(5.6)$ & $2.92(2.19-3.91)$ & $2,002(20.6)$ & $3.14(2.74-3.61)$ & $9,417(92.3)$ & $1.01(0.87-1.16)$ & $3,089(30.3)$ & $1.72(1.55-1.90)$ & $2,479(24.7)$ & $2.12(1.90-2.36)$ \\
\hline \multicolumn{11}{|c|}{ Number of hours spent using a smartphone on weekends } \\
\hline$<4$ & $131(1.6)$ & 1.00 & $656(8.4)$ & 1.00 & $7,500(92.6)$ & 1.00 & $1,529(18.6)$ & 1.00 & $1,113(13.9)$ & 1.00 \\
\hline$>4,<8$ & $220(2.0)$ & $1.06(0.82-1.36)$ & $1,435(13.0)$ & $1.53(1.37-1.70)$ & $10,673(93.0)$ & $1.08(0.95-1.22)$ & $2,632(23.0)$ & $1.20(1.11-1.30)$ & $2,160(19.2)$ & $1.43(1.31-1.56)$ \\
\hline$\geq 8$ & $460(6.0)$ & $2.64(2.06-3.38)$ & $1,618(21.6)$ & $2.77(2.45-3.13)$ & $7,294(92.0)$ & $1.01(0.87-1.16)$ & $2,491(31.8)$ & $1.69(1.55-1.84)$ & $1,975(25.6)$ & $2.02(1.84-2.21)$ \\
\hline \multicolumn{11}{|c|}{ Main purpose for using a smartphone } \\
\hline Education & $32(2.0)$ & 1.00 & $139(9.1)$ & 1.00 & $1,456(94.1)$ & 1.00 & $309(20.0)$ & 1.00 & $232(14.9)$ & 1.00 \\
\hline Communication & $642(3.9)$ & $1.91(1.26-2.91)$ & $2,699(16.6)$ & $2.43(1.96-3.02)$ & $15,448(92.4)$ & $0.89(0.71-1.13)$ & $4,237(25.4)$ & $1.22(1.05-1.41)$ & $3,369(20.5)$ & $1.44(1.23-1.70)$ \\
\hline Enjoyment & $137(1.5)$ & $0.74(0.48-1.16)$ & $871(10.0)$ & $1.34(1.07-1.67)$ & $8,563(92.7)$ & $0.93(0.73-1.19)$ & $2,106(22.5)$ & $1.05(0.90-1.22)$ & $1,647(18.3)$ & $1.27(1.07-1.51)$ \\
\hline Variables & \multicolumn{2}{|c|}{ Sleep disturbances } & \multicolumn{2}{|c|}{ Stress } & \multicolumn{2}{|c|}{ Depressive symptoms } & \multicolumn{2}{|c|}{ Suicidal ideation } & \multicolumn{2}{|c|}{ Suicide attempt } \\
\hline Total, N (\%) & $22,441(81.8)$ & OR (95\% CI)a & $12,440(44.8)$ & OR $(95 \% \mathrm{CI})^{*}$ & $8,424(30.5)$ & $\mathrm{OR}(95 \% \mathrm{CI})^{\dagger}$ & $4,214(15.2)$ & $\mathrm{OR}(95 \% \mathrm{CI})^{\ddagger}$ & $888(3.2)$ & $\mathrm{OR}(95 \% \mathrm{CI})^{\ddagger}$ \\
\hline \multicolumn{11}{|c|}{ Number of hours spent using a smartphone on weekdays } \\
\hline$<2$ & $4,618(79.5)$ & 1.00 & $2,454(41.8)$ & 1.00 & $1,491(25.4)$ & 1.00 & $759(13.1)$ & 1.00 & $149(2.5)$ & 1.00 \\
\hline$>2,<4$ & $9,277(81.1)$ & $1.08(0.99-1.19)$ & $4,946(42.8)$ & $1.02(0.95-1.08)$ & $3,232(28.1)$ & $1.11(1.02-1.21)$ & $1,548(13.2)$ & $0.93(0.83-1.04)$ & $287(2.4)$ & $0.86(0.68-1.08)$ \\
\hline$\geq 4$ & $8,546(84.0)$ & $1.32(1.19-1.47)$ & $5,040(49.0)$ & $1.23(1.14-1.33)$ & $3,701(36.4)$ & $1.42(1.30-1.56)$ & $1,907(18.6)$ & $1.08(0.96-1.21)$ & $452(4.4)$ & $1.13(0.90-1.42)$ \\
\hline \multicolumn{11}{|c|}{ Number of hours spent using a smartphone on weekends } \\
\hline$<4$ & $6,308(78.6)$ & 1.00 & $3,316(41.0)$ & 1.00 & $2,086(25.9)$ & 1.00 & $998(12.5)$ & 1.00 & $197(2.5)$ & 1.00 \\
\hline$>4,<8$ & $9,427(82.2)$ & $1.18(1.09-1.28)$ & $5,073(44.0)$ & $1.08(1.02-1.15)$ & $3,431(29.9)$ & $1.13(1.04-1.22)$ & $1,632(14.1)$ & $1.03(0.92-1.14)$ & $298(2.5)$ & $0.87(0.70-1.08)$ \\
\hline$\geq 8$ & $6,706(84.8)$ & $1.46(1.32-1.61)$ & $4,051(50.3)$ & $1.34(1.24-1.44)$ & $2,907(36.7)$ & $1.35(1.24-1.47)$ & $1,584(19.7)$ & $1.25(1.11-1.41)$ & $393(4.9)$ & $1.29(1.04-1.59)$ \\
\hline \multicolumn{11}{|c|}{ Main purpose for using a smartphone } \\
\hline Education & $1,202(78.3)$ & 1.00 & $712(46.3)$ & 1.00 & $441(28.8)$ & 1.00 & $2,574(15.3)$ & 1.00 & $42(2.8)$ & 1.00 \\
\hline Communication & $13,857(83.1)$ & $1.53(1.32-1.78)$ & $7,549(44.7)$ & $0.95(0.86-1.06)$ & $5,321(31.7)$ & $1.11(0.97-1.28)$ & $1,435(15.3)$ & $1.04(0.87-1.24)$ & $544(3.2)$ & $0.88(0.63-1.23)$ \\
\hline Enjoyment & $7,382(80.1)$ & $1.27(1.11-1.48)$ & $4,179(44.8)$ & $0.96(0.86-1.07)$ & $2,662(28.7)$ & $0.96(0.83-1.12)$ & $205(13.1)$ & $1.14(0.95-1.36)$ & $302(3.2)$ & $0.96(0.68-1.36)$ \\
\hline
\end{tabular}

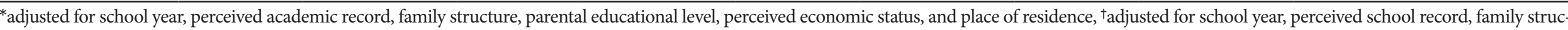

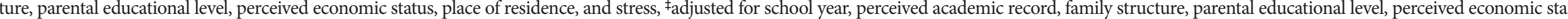
tus, place of residence, stress, and depressive symptoms. OR: odds ratio, CI: confidence interval 
Supplementary Table 2-1. Association between conflicts with family and friends and academic problems owing to smartphone use, unhealthy behaviors, and mental health status among boys

\begin{tabular}{|c|c|c|c|c|c|c|c|c|c|c|}
\hline \multirow{2}{*}{ Variables } & \multicolumn{2}{|c|}{ Smoking } & \multicolumn{2}{|c|}{ Drinking } & \multicolumn{2}{|c|}{ Physical inactivity $\geq 3$ days/week } & \multicolumn{2}{|c|}{ Skipping breakfast $\geq 5$ times/week } & \multicolumn{2}{|c|}{ Eating fast food $\geq 3$ times/week } \\
\hline & $\mathrm{N}(\%)$ & OR $(95 \% \mathrm{CI}) *$ & $\mathrm{~N}(\%)$ & OR (95\% CI)a & $\mathrm{N}(\%)$ & OR $(95 \% \mathrm{CI})^{*}$ & $\mathrm{~N}(\%)$ & OR $(95 \% \mathrm{CI})^{*}$ & $\mathrm{~N}(\%)$ & OR $(95 \% \mathrm{CI})^{*}$ \\
\hline \multicolumn{11}{|c|}{ Severe conflicts with family owing to smartphone use } \\
\hline No & $1,880(9.2)$ & 1.00 & $3,847(18.5)$ & 1.00 & $16,993(79.9)$ & 1.00 & $4,991(23.1)$ & 1.00 & $4,280(20.4)$ & 1.00 \\
\hline Yes & $548(10.2)$ & $1.30(1.16-1.47)$ & $988(18.6)$ & $1.17(1.07-1.28)$ & $4,355(81.3)$ & $1.16(1.07-1.27)$ & $1,138(21.0)$ & $0.89(0.83-0.96)$ & $1,372(26.1)$ & $1.40(1.30-1.50)$ \\
\hline \multicolumn{11}{|c|}{ Severe conflicts with friends owing to smartphone use } \\
\hline No & $1,815(8.8)$ & 1.00 & $3,689(17.6)$ & 1.00 & $17,004(79.1)$ & 1.00 & $5,021(23.0)$ & 1.00 & $4,337(20.4)$ & 1.00 \\
\hline Yes & $613(11.9)$ & $1.13(1.01-1.27)$ & $1,146(22.5)$ & $1.08(0.99-1.18)$ & $4,344(84.4)$ & $1.32(1.20-1.45)$ & $1,108(21.6)$ & $0.93(0.85-1.00)$ & $1,315(26.0)$ & $1.31(1.22-1.42)$ \\
\hline \multicolumn{11}{|c|}{ Academic problems owing to smartphone use } \\
\hline No & $2,251(9.0)$ & 1.00 & $4,587(18.1)$ & 1.00 & $20,739(80.2)$ & 1.00 & $5,918(22.6)$ & 1.00 & $5,402(21.2)$ & 1.00 \\
\hline Yes & $177(23.2)$ & $3.07(2.49-3.78)$ & $248(32.7)$ & $2.37(1.99-2.83)$ & $609(78.3)$ & $0.93(0.78-1.12)$ & $211(27.4)$ & $1.21(1.02-1.43)$ & $250(32.5)$ & $1.74(1.48-2.03)$ \\
\hline \multirow{2}{*}{ Variables } & \multicolumn{2}{|c|}{ Sleep disturbances } & \multicolumn{2}{|c|}{ Stress } & \multicolumn{2}{|c|}{ Depressive symptoms } & \multicolumn{2}{|c|}{ Suicide ideation } & \multicolumn{2}{|c|}{ Suicide attempt } \\
\hline & $\mathrm{N}(\%)$ & OR $(95 \% \mathrm{CI})^{*}$ & $\mathrm{~N}(\%)$ & OR $(95 \% \mathrm{CI})^{*}$ & $\mathrm{~N}(\%)$ & OR $(95 \% \mathrm{CI})^{\dagger}$ & $\mathrm{N}(\%)$ & OR $(95 \% \mathrm{CI})^{\ddagger}$ & $\mathrm{N}(\%)$ & OR $(95 \% \mathrm{CI})^{\ddagger}$ \\
\hline \multicolumn{11}{|c|}{ Severe conflicts with family owing to smartphone use } \\
\hline No & $14,640(69.2)$ & 1.00 & $5,965(27.9)$ & 1.00 & $3,862(18.2)$ & 1.00 & $1,695(7.9)$ & 1.00 & $334(1.5)$ & 1.00 \\
\hline Yes & $3,909(73.6)$ & $1.35(1.25-1.46)$ & $2,181(40.3)$ & $1.79(1.67-1.92)$ & $1,564(28.9)$ & $1.56(1.44-1.70)$ & $805(14.8)$ & $1.44(1.28-1.62)$ & $165(3.0)$ & $1.38(1.11-1.71)$ \\
\hline \multicolumn{11}{|c|}{ Severe conflicts with friends owing to smartphone use } \\
\hline No & $14,453(67.6)$ & 1.00 & $6,037(27.8)$ & 1.00 & $3,908(18.2)$ & 1.00 & $1,755(8.1)$ & 1.00 & $371(1.7)$ & 1.00 \\
\hline Yes & $4,096(80.0)$ & $1.59(1.47-1.73)$ & $2,109(40.9)$ & $1.71(1.59-1.83)$ & $1,518(29.0)$ & $1.46(1.33-1.60)$ & $745(14.2)$ & $1.31(1.16-1.48)$ & $128(2.5)$ & $1.07(0.85-1.35)$ \\
\hline \multicolumn{11}{|c|}{ Academic problems owing to smartphone use } \\
\hline No & $17,978(70.0)$ & 1.00 & $7,750(29.9)$ & 1.00 & $5,079(19.7)$ & 1.00 & $2,333(8.9)$ & 1.00 & $441(1.7)$ & 1.00 \\
\hline Yes & $571(73.9)$ & $1.25(1.06-1.48)$ & $396(50.0)$ & $2.28(1.94-2.68)$ & $347(45.7)$ & $2.78(2.31-3.34)$ & $167(22.0)$ & $1.38(1.10-1.73)$ & $58(7.2)$ & $2.18(1.55-3.08)$ \\
\hline
\end{tabular}

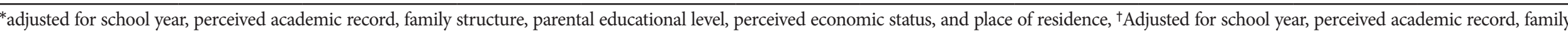

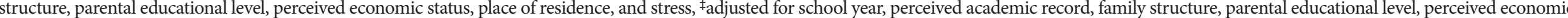
status, place of residence, stress, and depressive symptoms. OR: odds ratio, CI: confidence interval 
Supplementary Table 2-2. Association between conflicts with family and friends and academic problems owing to smartphone use, unhealthy behaviors, and mental health status among girls

\begin{tabular}{|c|c|c|c|c|c|c|c|c|c|c|}
\hline \multirow{2}{*}{ Variables } & \multicolumn{2}{|c|}{ Smoking } & \multicolumn{2}{|c|}{ Drinking } & \multicolumn{2}{|c|}{ Physical inactivity $\geq 3$ days/week } & \multicolumn{2}{|c|}{ Skipping breakfast $\geq 5$ times/week } & \multicolumn{2}{|c|}{ Eating fast food $\geq 3$ times/week } \\
\hline & $\mathrm{N}(\%)$ & OR $(95 \% \mathrm{CI})^{*}$ & $\mathrm{~N}(\%)$ & OR $(95 \% \mathrm{CI})^{*}$ & $\mathrm{~N}(\%)$ & OR $(95 \% \mathrm{CI})^{*}$ & $\mathrm{~N}(\%)$ & OR $(95 \% \mathrm{CI})^{*}$ & $\mathrm{~N}(\%)$ & OR $(95 \% \mathrm{CI})^{*}$ \\
\hline \multicolumn{11}{|c|}{ Severe conflicts with family owing to smartphone use } \\
\hline No & $557(2.8)$ & 1.00 & $2,711(13.5)$ & 1.00 & $19,340(92.5)$ & 1.00 & $5,072(24.2)$ & 1.00 & $3,723(18.0)$ & 1.00 \\
\hline Yes & $254(3.8)$ & $1.58(1.33-1.88)$ & $998(15.5)$ & $1.41(1.29-1.54)$ & $6,127(92.9)$ & $1.16(1.03-1.30)$ & $1,580(23.9)$ & $0.99(0.92-1.06)$ & $1,525(23.6)$ & $1.43(1.32-1.55)$ \\
\hline \multicolumn{11}{|c|}{ Severe conflicts with friends owing to smartphone use } \\
\hline No & $560(3.0)$ & 1.00 & $2,368(12.7)$ & 1.00 & $17,654(91.8)$ & 1.00 & $4,605(23.7)$ & 1.00 & $3,299(17.3)$ & 1.00 \\
\hline Yes & $251(3.0)$ & $0.85(0.72-1.00)$ & $1,341(16.7)$ & $1.15(1.05-1.25)$ & $7,813(94.3)$ & $1.42(1.26-1.60)$ & $2,047(24.8)$ & $1.04(0.97-1.11)$ & $1,949(23.9)$ & $1.44(1.34-1.55)$ \\
\hline \multicolumn{11}{|c|}{ Academic problems owing to smartphone use } \\
\hline No & $706(2.7)$ & 1.00 & $3,455(13.6)$ & 1.00 & $24,442(92.7)$ & 1.00 & $6,325(23.9)$ & 1.00 & $4,933(19.1)$ & 1.00 \\
\hline Yes & $105(9.4)$ & $3.43(2.50-4.70)$ & $254(22.6)$ & $2.18(1.84-2.60)$ & $1,025(91.5)$ & $1.00(0.78-1.27)$ & $327(29.0)$ & $1.20(1.02-1.42)$ & $315(27.6)$ & $1.58(1.36-1.83)$ \\
\hline \multirow{2}{*}{ Variables } & \multicolumn{2}{|c|}{ Sleep disturbances } & \multicolumn{2}{|c|}{ Stress } & \multicolumn{2}{|c|}{ Depressive symptoms } & \multicolumn{2}{|c|}{ Suicide ideation } & \multicolumn{2}{|c|}{ Suicide attempt } \\
\hline & $\mathrm{N}(\%)$ & $\mathrm{OR}(95 \% \mathrm{CI})^{*}$ & $\mathrm{~N}(\%)$ & OR $(95 \% \mathrm{CI})^{*}$ & $\mathrm{~N}(\%)$ & $\mathrm{OR}(95 \% \mathrm{CI})^{\dagger}$ & $\mathrm{N}(\%)$ & OR $(95 \% \mathrm{CI})^{\ddagger}$ & $\mathrm{N}(\%)$ & $\mathrm{OR}(95 \% \mathrm{CI})^{\ddagger}$ \\
\hline \multicolumn{11}{|c|}{ Severe conflicts with family owing to smartphone use } \\
\hline No & $16,816(80.6)$ & 1.00 & $8,652(40.9)$ & 1.00 & $5,599(26.7)$ & 1.00 & $2,550(12.1)$ & 1.00 & $524(2.4)$ & 1.00 \\
\hline Yes & $5,625(85.6)$ & $1.57(1.44-1.71)$ & $3,788(57.0)$ & $2.01(1.89-2.14)$ & $2,825(42.3)$ & $1.69(1.58-1.81)$ & $1,664(24.8)$ & $1.65(1.52-1.80)$ & $364(5.4)$ & $1.47(1.25-1.72)$ \\
\hline \multicolumn{11}{|c|}{ Severe conflicts with friends owing to smartphone use } \\
\hline No & $15,243(79.4)$ & 1.00 & $7,923(40.7)$ & 1.00 & $5,197(26.8)$ & 1.00 & $2,600(13.4)$ & 1.00 & $593(3.1)$ & 1.00 \\
\hline Yes & $7,198(86.9)$ & $1.49(1.37-1.63)$ & $4,517(53.9)$ & $1.62(1.53-1.71)$ & $3,227(38.5)$ & $1.43(1.34-1.53)$ & $1,614(19.0)$ & $1.16(1.07-1.26)$ & $295(3.4)$ & $0.88(0.75-1.03)$ \\
\hline \multicolumn{11}{|c|}{ Academic problems owing to smartphone use } \\
\hline No & $21,480(81.6)$ & 1.00 & $11,707(44.0)$ & 1.00 & $7,787(29.4)$ & 1.00 & $3,857(14.5)$ & 1.00 & $783(2.9)$ & 1.00 \\
\hline Yes & $961(85.8)$ & $1.53(1.25-1.88)$ & $733(64.3)$ & $2.34(2.02-2.71)$ & $637(56.8)$ & $2.50(2.19-2.86)$ & $357(31.6)$ & $1.42(1.18-1.70)$ & $105(9.2)$ & $1.65(1.26-2.16)$ \\
\hline
\end{tabular}

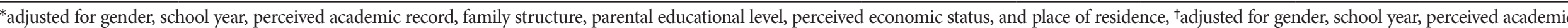

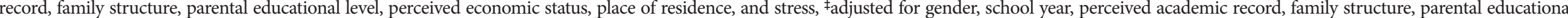
level, perceived economic status, place of residence, stress, and depressive symptoms. OR: odds ratio, CI: confidence interval 